\title{
Infant and Child Development
}

\section{Changes and challenges in $\mathbf{2 0}$ years of research into the development of executive functions}

\begin{tabular}{|c|c|}
\hline Journal: & Infant and Child Development \\
\hline Manuscript ID: & ICD-11-0050 \\
\hline Wiley - Manuscript type: & Research Article \\
\hline Keywords: & $\begin{array}{l}\text { executive function, neuroscience, autism, ADHD, social } \\
\text { understanding }\end{array}$ \\
\hline Abstract: & $\begin{array}{l}\text { This review of } 20 \text { years of developmental research on Executive } \\
\text { Functions (EF) offers a broad-brushstroke picture that touches on } \\
\text { multiple issues including: (i) findings from typical and atypical } \\
\text { groups, from infancy to adolescence; (ii) advances in assessment } \\
\text { tools and in statistical analysis; (iii) the interplay between EF and } \\
\text { other cognitive systems (e.g., those involved in children's } \\
\text { developing understanding of mind, and in their processing of } \\
\text { reward signals); (iv) integration of cognitive and neuroscience } \\
\text { perspectives on EF; and ( } \mathrm{v} \text { ) environmental factors that have either } \\
\text { a positive influence (e.g., training/intervention programmes; } \\
\text { parental scaffolding) or a negative influence (e.g., maltreatment, } \\
\text { neglect, traumatic brain injury) on EF. Of the several themes to } \\
\text { emerge from this review, two are particularly important; these } \\
\text { concern the need to adopt developmental perspectives and the } \\
\text { potential importance for intervention work of research on social } \\
\text { influences on EF. Specifically, the review highlights both } \\
\text { developmental continuities (e.g., in the correlates of EF) and } \\
\text { contrasts (e.g., in the nature of EF and its neural substrates) and } \\
\text { calls for research that compares developmental trajectories for EF } \\
\text { in different groups (e.g., children with autism vs. ADHD). In } \\
\text { addition, findings highlight the importance of environmental } \\
\text { influences on EF and so support the development of interventions } \\
\text { to promote EF and hence improve children's academic and social } \\
\text { outcomes. }\end{array}$ \\
\hline
\end{tabular}

\section{SCHOLARONE Manuscripts}


Changes and challenges in 20 years of research into the development of executive functions

\author{
Claire Hughes
}

Centre for Family Research,

University of Cambridge,

Free School Lane, Cambridge CB2 3RF, UK

16

17

18

19

20

21

22

23

24

25

26

27

28

29

30

31

32

33

34

35

36

37

38

39

40

41

42

43

44

45

46

47

48

49

50

51

52

53

54

55

56

57

58

59

60

http://mc.manuscriptcentral.com/icd 
Abstract

This review of 20 years of developmental research on Executive Functions (EF) offers a broad-brushstroke picture that touches on multiple issues including: (i) findings from typical and atypical groups, from infancy to adolescence; (ii) advances in assessment tools and in statistical analysis; (iii) the interplay between EF and other cognitive systems (e.g., those involved in children's developing understanding of mind, and in their processing of reward signals); (iv) integration of cognitive and neuroscience perspectives on EF; and (v) environmental factors that have either a positive influence (e.g., training/intervention programmes; parental scaffolding) or a negative influence (e.g., maltreatment, neglect, traumatic brain injury) on EF. Of the several themes to emerge from this review, two are particularly important; these concern the need to adopt developmental perspectives and the potential importance for intervention work of research on social influences on EF. Specifically, the review highlights both developmental continuities (e.g., in the correlates of EF) and contrasts (e.g., in the nature of EF and its neural substrates) and calls for research that compares developmental trajectories for EF in different groups (e.g., children with autism vs. ADHD). In addition, findings from both family-based research and randomized controlled trials of school-based interventions highlight the importance of environmental influences on $\mathrm{EF}$ and so support the development of interventions to promote EF and hence improve children's academic and social outcomes. 
Executive Function (EF) is an umbrella term that encompasses the higher-order processes (such as inhibitory control, working memory, attentional flexibility) that govern goal-directed action and adaptive responses to novel or complex situations. For much of the last century, research on EF focused on adults rather than children; as noted elsewhere (Hughes \& Graham, 2002), this prolonged neglect of developmental perspectives on EF can be explained in at least three ways. First, the pre-frontal cortex, widely considered as the neural substrate for EF, was thought to mature very late, around adolescence (Golden, 1981). Second, primate studies and early research on head-injuries suggested that the consequences of juvenile lesions to the prefrontal cortex did not become apparent until adulthood (the so-called 'Kennard effect'). Third, because they were designed for adults, early EF tests were typically too difficult to be appropriate for use with children.

Over the past few decades, developmental EF research has grown exponentially: a recent Scopus search using the terms 'EF' and 'children' showed 26 hits between 1980 and 1990, 216 hits between 1990 and 2000, and 1,092 hits between 2000 and 2010. What insights have emerged from this remarkable increase in research interest in EF in childhood? To celebrate Infant and Child Development's $20^{\text {th }}$ birthday, this review addresses this question by considering developmental EF research over the journal's lifetime in relation to five themes. The first two of these concern the nature and significance of EF deficits in clinical groups and links between individual differences in EF and in children's understanding of mind. These two themes were central to an EF special issue of Infant and Child Development that appeared in 2005 (for an overview, see Hughes, 2002) and so are discussed only briefly in the current paper. The next two themes are the need to attend to methodological issues in both task design and in analysis and, building on this, the 
importance of adopting developmental perspectives to construct more dynamic models of individual differences in EF. Although methodological issues were discussed in the 2005 ICD special issue, recent years have seen striking progress in the analysis of data from developmental EF studies and so these themes are discussed in more detail in this paper. The final theme represents a shift from science to practice and consider social influences on EF development, including both positive and negative effects of family environments and the efficacy of school-based interventions.

\section{(1) EF deficits in clinical groups}

Over the past 20 years, EF deficits have been reported for numerous clinical groups, ranging in age from infancy through to adolescence. For example, in a landmark study, Diamond, Prevor, Callender and Druin (1997) examined very young children treated early and continuously for phenylketonuria (PKU), a metabolic disorder that affects infants' ability to convert phenylalanine to tyrosine (the precursor of dopamine) and that, if untreated, is the most common biochemical cause of developmental delay. Highlighting the importance of dopamine for EF, Diamond et al. (1997) found that, across all ages (6 months to 7 years) within the PKU group, high plasma levels of phenylalanine predicted poor performance on tests of working memory and inhibitory control.

More recent studies have revealed that premature birth and prenatal exposure to high levels of alcohol are also associated with long-term EF deficits. In a recent metaanalysis of EF in children born prematurely, Mulder, Pitchford, Hagger and Marlow (2009) found that severity of EF impairment was related to: (i) gestational age (extremely premature infants showed greater EF deficits); (ii) age at test (group differences attenuated with age); and (iii) aspect of EF under test ('catch-up' effects were evident for selective 
attention skills but not for attention set-shifting skills). EF deficits in children with prenatal alcohol exposure have yet to be systematically reviewed, but are widely reported to be independent of IQ (e.g., Connor, Sampson, Bookstein, Barr, \& Streissguth, 2000; Green et al., 2009; Mattson, Goodman, Caine, Delis, \& Riley, 1999; Schonfeld, Mattson, Lang, Delis, \& Riley, 2001) and distinct from EF deficits in other groups, such as children with attention deficit hyperactivity disorder (ADHD) (e.g., Vaurio, Riley, \& Mattson, 2008). Together, these findings highlight both the sensitivity of EF to neurological challenges and the fractionated nature of EF.

Moving on to preschool milestones, much of the clinical literature has concerned EF deficits in children with autism (for reviews, see Hill, 2004; Pennington \& Ozonoff, 1996). The breadth and sophistication of current research in this field are nicely illustrated by a handful of recent findings that include: (i) evidence for associations between impaired inhibitory control and high-level repetitive behaviors (e.g., compulsions, preoccupations) in children with autism spectrum disorders (Mosconi et al., 2009); (ii) experimental evidence that suggests that the deficits in pretend play shown by children with autism reflect impairments in generativity rather than in meta-representation of mental states (Jarrold, Mansergh, \& Whiting, 2010); (iii) imaging results that indicate reduced functional connectivity and network integration between frontal, parietal, and occipital regions among individuals with autism spectrum disorders completing EF tasks (Solomon et al., 2009); (iv) longitudinal evidence for the importance of early EF in shaping the developmental trajectory of theory-of-mind skills in children with autism spectrum disorders (Pellicano, 2010); and (v) evidence for age-related improvements in executive function from childhood 
to adolescence in autism, indicating the presence of plasticity and suggesting a prolonged window for effective treatment (for a review, see O'Hearn, Asato, Ordaz, \& Luna, 2008).

Among school-aged children, clinical EF studies typically focus on children with ADHD who, by definition, show marked problems of impulsivity / inattention / disorganization in their everyday lives. Interestingly, comparisons of clinical groups show that EF deficits are typically less pervasive and severe among children with ADHD than among children with autism (e.g., Geurts, Verté, Oosterlaan, Roeyers, \& Sergeant, 2004; Goldberg et al., 2005; but see also Happé, Booth, Charlton \& Hughes, 2006). As a result, contemporary causal accounts of ADHD (e.g., Sonuga-Barke, 2005) also include additional deficits in the signaling of delayed rewards.

In adolescence, clinical studies again highlight a close interplay between EF and reward systems. For example, poor EF and impulsivity in late childhood predict high levels of drug use in late adolescence (e.g., Aytaclar, Tarter, Kirisci, \& Sandy, 1999). Similarly, Wiers et al. (2007) proposed that repeated alcohol use in adolescence leads to compromised EF development coupled with sensitization of appetitive reward systems. In addition, Fairchild et al. (2009) found that although boys with conduct disorder (especially earlyonset conduct problems) showed no EF deficits when effects of IQ were controlled, they were more likely to make risky choices even for small gains, suggesting an atypical balance between sensitivity to reward and punishment. In short then, clinical studies of EF in older children and adolescents highlight the importance of examining the interplay between topdown EF systems and bottom-up reward processes; this interplay is discussed later on in this paper.

\section{2) Associations between individual differences in EF and in understanding of mind.}


Almost 20 years ago, researchers examining the factors underpinning autistic children's poor false belief performance highlighted associations with emerging EF skills (e.g., Hughes \& Russell, 1993; Ozonoff, Pennington, \& Rogers, 1991). Since then, research in this field has grown in at least three directions. The first of these is a dramatic growth in the variety of samples involved: there is now evidence for a robust association between $\mathrm{EF}$ and theory of mind in several different clinical groups, including children with autism (e.g., Pellicano, 2007), children with hyperactivity or conduct problems (Hughes, Dunn, \& White, 1998), children with traumatic brain injuries (Dennis, Agostino, Roncadin, \& Levin, 2009), and children with fetal alcohol syndrome (Rasmussen, Wyper, \& Talwar, 2009). In addition, amongst typically developing samples, this link between EF and understanding of mind has been documented at several different periods of development, from toddlerhood (e.g., Carlson, Mandell, \& Williams, 2004; Hughes \& Ensor, 2005) to adolescence (Dumontheil, Apperly, \& Blakemore, 2010).

Expanding the developmental scope of research into associations between EF and theory of mind has led to more nuanced theoretical accounts, including, for example, the proposal that the relationship between EF and theory of mind is developmentally dynamic. In particular, in a critique of the original theory-of-mind account of autism (which is often diagnosed long before children are expected to pass false belief tasks), Tager-Flusberg (2001) proposed that early-onset 'socio-perceptual' skills (aka intuitive mentalising) depend on modular cognitive processes, whereas later-onset 'socio-cognitive' skills (aka off-line mental-state reasoning) depend on other aspects of cognition, such as language and EF. This model of dual processes (e.g., Apperly, Samson, \& Humphreys, 2009; de Vignemont, 2009) also goes some way to explaining why typically-developing young 
children can show quite sophisticated mentalising skills in their everyday interactions and yet fail experimental false-belief tasks.

The second direction of growth in research on links between EF and theory of mind concerns the number of longitudinal studies; these have been conducted using a variety of age groups and also vary in temporal span, from short-term microgenetic studies (e.g., Flynn, 2006) to studies involving intervals of up to 24 months (Carlson, Mandell, \& Williams, 2004; Hughes \& Ensor, 2007). One consistent finding to emerge from all of these longitudinal studies is that early EF predicts later mental-state awareness more strongly than early mental-state awareness predicts later EF. Without going as far as stipulating that EF is, in some sense, necessary for the emergence of mental-state awareness, it seems reasonable to argue that EF improvements in the preschool years help explain how children make use of their early intuitive understanding of mind. The third and final direction of progress is the growth of studies that link EF and theory of mind to common neural substrates (for reviews, see Perner \& Aichhorn, 2008; Perner, Aichhorn, Kronbichler, Staffen, \& Ladurner, 2006). This literature is discussed at the end of the next section.

\section{3) Methodological issues in assessment and analysis}

The past 20 years have seen impressive and wide-ranging methodological improvements in research on EF in childhood. This section provides a brief summary of five distinct areas of improvement: (i) the development of child-friendly tasks; (ii) the development of computerized tasks; (iii) greater attention to issues of ecological validity; (iv) an increase in the rigor and sophistication of statistical analyses; and (v) the combination of neuropsychological and neuro-physiological assessments. 
Child-friendly tasks. As noted at the start of this review, the delayed emergence of developmental perspectives on EF can at least in part be explained by the scarcity of developmentally appropriate measures. Indeed, a dramatic increase in the availability of child-friendly tasks is perhaps the most striking change over the past two decades of developmental EF research. Moreover, studies of children's performances on these simpler tasks have, in many ways, minimized many of the problems associated with measuring EF in adults (Hughes \& Graham, 2002).

That said, as Garon, Bryson and Smith (2008) noted in their recent review (which includes a helpful summary of EF tasks for very young children), in simplifying EF tasks for children there is a real danger of losing the critical EF component. In addition, many EF tasks have relatively weak psychometric properties (e.g., Bishop, Aamodt-Leeper, Creswell, McGurk, \& Skuse, 2001). For each of these reasons, it is possible that agecontrasts in children's performances on EF tasks actually reflect non-EF influences on performance. This point has particular force for specific developmental periods (e.g., children's transition to school) that are characterized by improvements in salient non-EF factors (e.g., language ability, pragmatic understanding, and compliance). To address this concern, Hughes, Ensor, Wilson and Graham (2010) tracked children's EF scores from ages 4 to 6 (i.e., from preschool to school age). Their analyses showed that latent EF factors showed a reassuringly good fit to the data, even when potential effects of measurement artifacts were removed by holding the metric constant across time points.

Computerized tasks. From a research perspective, computerized tests of EF have a number of benefits; these include the ease of standardizing administration and collecting data from a large numbers of trials, including information about reaction times. One widely 
used battery of computerized EF tasks is the CANTAB (CAmbridge Neuropsychological Tests - Automated Battery), which was developed for work with adult clinical groups (Luciana, 2003) and was first administered to children in Hughes, Russell and Robbins' (1994) study of children with autism; subsequent studies have confirmed that the CANTAB is sensitive to EF deficits in autism across a wide range of ages and ability levels (Ozonoff et al., 2004). Normative data on age-related improvements in EF in typically developing children (screened to exclude children with learning or behavioral difficulties) have also been gathered (Luciana, 2003). However, computerized tasks appear less sensitive than manual tasks to EF deficits in clinical groups, such as children with autism (Ozonoff, 1995), and have also been criticized as having poor ecological validity, a topic that is considered in more detail below.

Ecological validity. Individuals with frontal damage often show intact performance on EF tasks, yet appear impulsive and disorganized in their everyday lives (Levine et al., 2000). Over the past 20 years, this issue of ecological validity has been addressed in two distinct ways. First, in a new generation of EF tasks, open-ended problems are used to index the 'multi-tasking' skills required by many practical situations (e.g., shopping or cooking). The first of these new tasks were designed for adults, but over the past decade a number of open-ended tasks have also been designed for children. For example, the children's version of the Behavioural Assessment of Dysexecutive Syndrome (BADS-C; Emslie, Wilson, Burden, Nimmo-Smith \& Wilson (2003) includes tests of practical problem solving (e.g., planning a trip around a zoo; conducting a systematic search of an area for a missing small object; using water to get a cork out of a container) and now has norms available for children aged 7 to 16 years. Interestingly, a recent study of autism that 
involved a battery of EF tasks showed that the open-ended tasks on the BADS-C were particularly sensitive to group differences between children with autism and their age- and IQ-matched controls (White, Burgess, \& Hill, 2009). Recently, another study involving older children and teenagers used a practical EF task in which participants display their multi-tasking skills by following recipe instructions for two simple dishes in tandem; scores on this cooking task show good test-retest reliability, converge with scores on other EF measures, and appear sensitive to the EF deficits shown by children with traumatic brain injury (Chevignard, Catroppa, Galvin, \& Anderson, 2010).

Second, researchers have begun to broaden the nature of EF assessments by including parent questionnaires designed to index children's everyday EF skills. For example, alongside the practical tasks described above, the BADS-C includes a parent questionnaire (DEX-C) that is now widely used for assessing children with a wide spectrum of developmental and acquired neurological conditions. Another such questionnaire is the 'Behavioral Rating Inventory of Executive Function' (BRIEF- Gioia, Isquith, Retzlaff, \& Espy, 2002), which includes a parallel teacher version that enables EF skills to be assessed in both home and school environments. The BRIEF provides 8 distinct scales, of which three (Inhibit, Shift, Emotional Control) index Behavioural Regulation and five (Initiate, Working Memory, Plan/Organize, Organization of Materials, Monitor) index Metacognition. These 8 scales are based on 86 items, such that the acronym BRIEF is perhaps somewhat misleading. However, a recent study has demonstrated that an abbreviated version of the parental questionnaire shows good psychometric properties (Lejeune et al., 2010). That said, another recent study (McAuley, Chen, Goos, Schachar, \& Crosbie, 2010) concluded that scores on the BRIEF provide a good index of everyday 
problems, but show relatively weak associations with scores on direct tests of EF. In contrast, Carlson and Wang (2007) reported that, for typically developing preschoolers at least, experimental measures of EF show strong associations with scores on a much older rating scale, designed to index normative individual differences and age-related changes in children's 'self control' (Kendall \& Wilcox, 1979). However, no study has examined EF task performances in relation to scores on both the BRIEF and the Self Control rating scales; this comparison is needed to rule out the possibility that these contrasting results reflect differences in the samples or in the ecological validity of the tasks used, rather than real differences in the constructs tapped by these two questionnaire measures.

Statistical Analyses. Studies of EF in childhood have also advanced through the use of more rigorous methods of statistical analysis, including confirmatory factor analysis (CFA), item response theory (IRT) and latent growth models (LGMs). For example, in a seminal study Miyake and colleagues (Miyake et al., 2000) used confirmatory factor analysis (CFA) to demonstrate 'unity and diversity' in the structure of EF in adults. Interestingly, subsequent studies that applied CFA to data from children suggest that EF in preschoolers has a simple unitary structure (e.g., Hughes, Ensor, Wilson, \& Graham, 2010; Wiebe, Espy, \& Charak, 2008; Wiebe et al., 2010), but shows a more fractionated structure in school-aged children (Huizinga, Dolan, \& van der Molen, 2006; Lehto, Juujärvi, Kooistra, \& Pulkkinen, 2003). That is, as noted by Wiebe et al. (2010), dramatic improvements in the efficiency of EF in the preschool years appear to be accompanied by fundamental changes in the structure of EF.

Very recently, Willoughby, Wirth and Blair (2010) have applied IRT to assess the psychometric properties of a battery of EF tasks for preschoolers. IRT is an example of 
modern measurement theory, and addresses several problematic assumptions inherent within classical test theory (CTT). In particular, CTT assumes that: (i) individual items on a given task are interchangeable (such that actual scores reflect true ability); and (ii) measurement precision for a task does not vary for children of different ability levels (such that task scores work equally well for distinct subgroups of children). In contrast, IRT allows one to plot 'item characteristic curves' (ICCs) that provide information about both the difficulty and discrimination of specific items within a task; the information in these ICCs can then be aggregated to provide 'total information curves' that summarize how well a particular task discriminates between performance across children of varying abilities. In addition, IRT allows one to test for differential item functioning by comparing item parameters (e.g., difficulty, discrimination) across different groups (e.g., boys / girls; preschoolers / school-aged children; participants from low / high income families). Applying this approach, Willoughby et al. (2010) were able to show that three distinct EF tasks (a self-ordered search test of working memory, a 'Silly Sounds' non-verbal Stroop test of inhibitory control, and an attention set shifting task) showed similar ICCs over repeated intervals and for children from low-income vs. high income families, but differed markedly with regard to task information. Specifically, the inhibitory control task provided very good reliability over a narrow range of ability, but the working memory and attentional set shifting task provided moderate reliability over a broad range of ability levels. These contrasts in psychometric properties highlight the challenges facing researchers investigating developmental change in the nature of EF and indicate that conclusions about structural change (e.g., a shift from a unitary to a fractionated construct) can only be made with considerable caution. 
To add to the complexity, studies of age-related improvements in EF performance often overlook variation in growth, but recent work using latent growth models (LGMs) highlight the importance of attending to individual differences in the rate at which children improve their EF skills. Specifically, in a study that tracked EF skills for 191 children who were followed from age 4 to age 6 (i.e., across the transition to school), Hughes and Ensor (2010) found that, even when effects of concurrent individual differences in verbal ability and EF were controlled, variation in EF slopes predicted individual differences in both teacher-rated problem behaviours and self-rated academic competence. That is, when assessing the relationship between children's cognitive performance and their behavior / self-concepts, children's growth (rather than their actual performance) appears to be what really matters.

Integration with neurophsyiological assessments. Over the past two decades, a key advance within research on EF development has been the increased integration between cognitive and neuroscience perspectives. For example, recent studies using functional magnetic resonance imaging (fMRI - for a review, see Tau \& Peterson, 2010) have been able to confirm the view that developmental improvements in EF coincide with age-related increases in the activation of dopamine rich frontal and striatal circuits. This integration of cognitive and biological assessments has, in turn, led to greater recognition of the interplay between social and biological influences on children's development. This is well illustrated by recent findings that provide a fresh perspective on the mechanisms underpinning associations between EF and theory of mind (discussed earlier).

Specifically, alongside evidence that dopaminergic systems are involved in children's EF development, findings from recent studies using electro-encephalogram 
(EEG) recordings suggest that dopamine pathways are also implicated in children's growing understanding of mind (Sabbagh, Bowman, Evraire, \& Ito, 2009). Moreover, dopamine systems may contribute to social influences upon children's growing understanding of mind (Lackner, Bowman, \& Sabbagh, 2010). Specifically, by regulating the activity of fronto-striatal circuits in order to respond flexibly to environmental feedback (e.g., Montague, Hyman, \& Cohen, 2004), dopamine is likely to contribute to children's ability to reflect on (and revise) their own concepts of mind in order to accommodate new information from the environment. Variation in this ability to shift expectations and goals (e.g., as indexed by strategic decision-making in gambling tasks) may, in turn, be pivotal to accounts of how family environment factors (such as frequencies of family conversations about mental states, or interactions with siblings) lead to individual differences in children's theory-of-mind development (Perner, Ruffman, \& Leekam, 1994). In other words, alongside possible mediation effects of social interactions on the relation between EF and theory of mind, EF (and closely related reward functions of the dopaminergic systems) may moderate the impact of social interactions on children's developing understanding of mind. To my knowledge, this proposal has yet to be tested.

\section{4) Developmental perspectives}

Both the pervasiveness of EF deficits in childhood disorders and the salience of EF for studies of normal brain development can be understood in terms of the protracted nature of EF development. EF skills begin to emerge in infancy (Diamond, 1988), show marked improvements across toddlerhood and the preschool period (Carlson, Mandell, \& Williams, 2004; Hughes \& Ensor, 2007; Hughes, Ensor, Wilson, \& Graham, 2010) and continue to improve across the school years (e.g., Huizinga, Dolan, \& van der Molen, 2006), with some 
aspects of EF continuing to develop throughout adolescence (Luciana, Conklin, Cooper, \& Yarger, 2005; Luna, Garver, Urban, Lazar, \& Sweeney, 2004). Interestingly, although several reviews of EF development are available (e.g., P. Anderson, 2002; Best, Miller, \& Jones, 2009; Blair, Zelazo, \& Greenberg, 2005; Blakemore \& Choudhury, 2006; Garon, Bryson, \& Smith, 2008; Hughes \& Graham, 2002) very few span the full period of development (for an exception, see Diamond, 2002). To rectify this gap, this section provides a brief outline of key findings from developmental studies of EF, from infancy to adolescence.

Infancy. Evidence that EF emerges in the first year of life first came from studies using Piaget's object permanence task, in which babies are repeatedly allowed to retrieve an attractive object from one location (A) before seeing it hidden at a new location (B). Early studies indicated that while babies aged 8 months or older typically search correctly at location B, 5-month-olds persist in searching for the object at location A (e.g., Harris, 1975). However, later studies that used looking times rather than physical reaches to assess perceptual understanding, showed that even 5-month-olds could succeed on this task (e.g., Baillargeon, Spelke, \& Wasserman, 1985; Cuevas \& Bell, 2010). Thus young babies who make the 'A not B' error in their reaching responses may know that the object has been moved, but fail to inhibit their previously successful (and thus prepotent) reach to A. Success on this task can therefore be seen as reflecting infants' growing cognitive flexibility and volitional control (Diamond \& Goldman-Rakic, 1989). Other tasks that also demonstrate early executive skills in infancy include a detour-reaching task, in which infants are invited to retrieve an object that is visible behind a Perspex screen; success on this task depends on making a 'detour reach' around the side of the screen (Diamond, Zola- 
Morgan, \& Squire, 1989). On this task, a rudimentary ability to inhibit prepotent responses is clearly evident by 7-12 months (Diamond, 2002).

More recent infant studies also indicate an early emergence of other aspects of EF, such as executive attention. For example, building on Rothbart, Ellis, Rueda and Posner's (2003) finding that anticipatory looking (i.e., looking to the location of a target prior to its appearance) in 2-year-olds is associated with parental ratings of self-regulation, Sheese and colleagues (Sheese, Rothbart, Posner, White, \& Fraundorf, 2008) reported that 6- and 7month-olds who display high levels of anticipatory looking also show more signs of selfregulation in their approach towards novel toys. Interestingly, in this study anticipatory looking was also associated with looking away from disturbing stimuli (face masks), supporting proposed links between early systems of emotional and cognitive control (e.g., Aksan \& Kochanska, 2004; Rothbart, Derryberry, \& Hershey, 2000).

Preschoolers. Research into the preschool years accounts for the lion's share of recent studies of EF in childhood. This focus on preschoolers reflects both the intensity of research into preschoolers' understanding of mind and the recent availability of ageappropriate tasks. However, even when these conceptual and methodological factors are taken into account, the growth of research on preschool EF remains remarkable and is difficult to summarize briefly. Fortunately, Garon et al.'s (2008) recent comprehensive review is helpful in at least two respects. First, addressing the question of how to characterize developmental changes in EF across the preschool years, Garon et al. (2008) highlight the importance of age-related improvements in attention and coordination of distinct EF components. As they observe, attention also appears central to theoretical accounts that characterize EF development in terms of increased ability to integrate 
conflicting rules (Zelazo, Muller, Frye, \& Marcovitch, 2003) or to overcome prepotent thoughts / acts (Diamond, 2002) or latent representations (Munakata, 2001).

Second, Garon et al. (2008) offer a number of suggestions for future research. One suggestion (discussed more fully in the next section of this paper) concerns the importance of studying environmental influences on EF. Another suggestion concerns the need for studies of developmental changes in EF to adopt a longitudinal design in order to control for individual differences in EF. In one such study, Hughes et al. (2010) found: (i) measurement invariance across latent factors for EF in preschool and early school age (supporting the validity of across-time comparisons of average EF performance); (ii) positive associations between variation in preschool EF and differences in both maternal education and early child verbal ability; and (iii) inverse relations between rates of growth in EF and verbal ability (such that preschoolers with low verbal ability begin to catch up with their peers following the transition to school) but not maternal education (i.e., children with less educated mothers show no independent catch-up effect). As these findings illustrate, adopting longitudinal study designs to examine developmental trajectories in early EF is valuable, both theoretically and for the development of educational policy.

School age. A key finding to emerge from studies of EF across the school years is that step-wise improvements are evident at different ages for different aspects of EF. For example, while (as noted earlier) the preschool years are characterized by dramatic improvements in inhibitory control, studies of young school-aged children highlight improvements in cognitive flexibility. For example, Luciana (2003) reported that around the age of 6 or 7 years children showed a marked improvement in their ability to shift mental set (e.g., to attend to a previously irrelevant dimension when choosing which of two 
stimulus patterns is 'correct' - in a multi-stage task based on the Wisconsin Card Sorting Task), whereas clear improvements on the Tower of London planning task or on a selfordered search test of working memory in the CANTAB were often not evident before the age of 11 or 12 years. Other studies using different tasks have reported a similar contrast in the developmental trajectories of different aspects of EF. For example, several studies report improvements in mental flexibility around age 8 years (e.g., P. Anderson, 2002; W. W. Anderson, Damasio, Tranel, \& Damasio, 2001) while planning, organizing and strategic thinking are typically reported to emerge later and to show age-related improvements throughout adolescence (P. Anderson, Anderson, \& Garth, 2001; P. Anderson, Anderson, \& Lajoie, 1996; De Luca et al., 2003; Krikorian, Bartok, \& Gay, 1994; Welsh, Pennington, \& Groisser, 1991).

At odds with this general pattern, however, are findings from another study that suggest a long developmental progression for cognitive flexibility, with 13-year-olds still not at adult levels (Davidson, Amso, Anderson, \& Diamond, 2006). A closer look at the specific tasks suggests that the contrast in these findings may be explained by Diamond's (2009) 'all or none' theory. According to this theory, the brain and mind work effortlessly at a gross level, but require effort, to work in a more selective manner, such that it is easier to inhibit a dominant response all the time than only some of the time. As a result, even older children are likely to show frequent errors on tasks (such as that used in Davidson et al.'s (2006) study) involving 'mixed block' designs that require them to switch repeatedly between dominant and sub-dominant responses,. This study also revealed several other interesting developmental contrasts. For example, adults slowed down on difficult trials to preserve accuracy but children (and especially young children) were impulsive and so 
made errors on difficult trials. These contrasting speed accuracy trade-offs highlight the value of using computerized tasks to assess EF.

Adolescence. Recent technological advances have also led to significant progress in documenting parallels between milestones in EF development in adolescence and changes in brain myelination. This progress is particularly evident in Giedd et al.'s (1999) largescale longitudinal MRI work on adolescence, which has shown that this period is characterized by both a linear increase in white matter and a non-linear decrease in grey matter. Gains in white matter have clear functional consequences, which include faster and more efficient sharing of information within the fronto-striatal circuits and smoother communication between the frontal cortex and other brain regions (Paus, 2010). Peak periods of reduction in grey matter occur just after puberty and at the transition from adolescence to adulthood; although typically attributed to synaptic pruning, this 'loss' of grey matter may simply reflect gains in white matter (Paus, 2010). As noted in a recent review (Blakemore \& Choudhury, 2006), structural changes in the adolescent brain are particularly evident in the frontal cortex and are linked to age-related improvements in inhibitory control (Luna, Garver, Urban, Lazar, \& Sweeney, 2004), working memory (e.g., Luciana, Conklin, Cooper, \& Yarger, 2005) and decision-making (e.g., Hooper, Luciana, Conklin, \& Yarger, 2004).

Consistent with the findings from younger samples described above, different aspects of EF have been reported to show distinct trajectories across the adolescent years. For example, in a study of Australian 11- to 17-year-olds that included a variety of EF tasks, Anderson, Anderson, Northam, Jacobs and Catroppa (2001) found clear linear age- 
related improvements on tests of selective attention, working memory and problem solving, but no age-related difference in planning performance.

Also echoing findings from studies of younger samples is an emerging theme from the adolescent literature regarding the need to consider individual differences in both the maturity of adolescents' EF functions and the extent to which they avoid risk and respond to reward / peer influence (adolescents are less risk-averse, more driven by reward, and more easily influenced by peers). Thus accounts of developmental change in everyday behavior should consider the interplay between top-down EF systems and bottom-up motivational and emotional responses to situations of risk and reward.

Similar conclusions emerge from a recent community-based study of relations between EF, problem behaviors and risk-taking in 10-12-year-olds (Romer et al., 2009). In this study, the children's self-reported impulsivity was inversely related to both working memory and reversal learning and explained individual differences in both externalizing problems and performance on a risk-taking task. Noting that interventions to improve children's working memory have led to reductions in impulsive behaviors (e.g., Klingberg et al., 2005), the authors of this study concluded that young people who have difficulties in considering multiple (and potentially conflicting) goals will be less likely either to 'look before they leap' or to temper their interest in novel or exciting experiences.

\section{5) Social influences on EF development}

The frontal cortex and its networks mature very gradually and so are heavily dependent on the environment (e.g., Noble, Norman, \& Farah, 2005). Yet, compared with the large body of biological studies of EF development (for a recent review of molecular genetic studies of EF in children, see Brocki, Clerkin, Guise, Fan, \& Fossella, 2009), very few studies have 
examined the processes underpinning environmental influences on EF. This lack of empirical research is surprising, given that an emphasis on the importance of social influences on EF is prominent in both early theoretical work (e.g., Luria, 1966; Vygotsky, 1978) and more recent accounts (Lewis \& Carpendale, 2009). That said, work in this field is now growing rapidly and currently encompasses at least three key issues: (i) positive influences of parent-child interactions on EF; (ii) effects of adverse family environments; and (iii) effects of training or intervention programs. These are described in more detail below.

Positive effects of parent child interactions. Carlson (2003) has proposed that three dimensions of adult-child interactions are likely to favour child EF. The first two of these scaffolding (which provides children with successful experiences of problem-based learning) and mind-mindedness (which provides children with verbal tools for progressing from external to internal forms of self-regulation) - each feature prominently in two randomized controlled trials (discussed below). Positive effects on EF of the third dimension of sensitivity (which provides infants with successful experiences of impacting on the environment) have been reported by Bernier, Carlson and Whipple (2010), in their recent longitudinal study of 80 infants, in which all three dimensions of parenting (evaluated at 12 to 15 months of age) predicted EF at 18 and 26 months. Once effects of maternal education and general cognitive ability were taken into account, however, scaffolding was the strongest predictor of EF at each age. Another recent study, conducted by Bibok, Carpendale and Muller (2009), offers a refinement of how parental scaffolding may promote young children's EF skills (indexed by performance on an attentionswitching task). Specifically, observations of parents scaffolding children's goal-directed 
activities revealed that the timing of parents' elaborative utterances was a key predictor of children's attention-switching skills.

In short, there is now good evidence that parents' deliberate efforts to scaffold children's goal-directed activities do indeed foster the development of early EF skills. But, as highlighted by research on children's developing social understanding, family influences are often incidental rather than deliberate. Support for this view comes from a recent longitudinal observational study by Hughes and Ensor (2009) involving a socially diverse sample of 125 children. In this study both maternal scaffolding (in structured play with jigsaws) and opportunities for observational learning (indexed by maternal strategic behavior in a multi-tasking paradigm and in a shared tidy-up task) predicted improvements between the ages of 2 and 4 in children's EF scores, even when effects of verbal ability were controlled. Note that including EF assessments at both time-points enabled Hughes and Ensor (2009) to take the temporal stability of individual differences in EF into account, and so minimize the confounding effects of genetic factors (Kovas, Haworth, Dale, \& Plomin, 2007).

Negative effects of adverse family environments. Alongside the positive associations between EF and both deliberate and incidental opportunities to learn from parents' planful behaviour, Hughes and Ensor (2009) also found that EF development from age 2 to age 4 was negatively correlated with parental ratings of disorganised and unpredictable family life, suggesting that families can hinder as well as help young children's emerging EF skills. Indeed, clinical studies indicate that unfavourable early environmental experiences adversely affect both brain structure (e.g., De Bellis, 2005) and function (e.g., Rutter \& O'Connor, 2004). These adverse effects may be especially clear for 
children's developing EF skills. For example, a recent study of internationally adopted children (exposed to severe adverse early environments) demonstrated good catch-up in many specific areas of development, but persistent difficulties in EF and attentional regulation (Jacobs, Miller, \& Tirella, 2010). Other clinical studies of children who have experienced maltreatment or severe neglect highlight the impact of such extreme adverse environments on neuroendocrine and autonomic stress reactivity, which in turn leads to increased demands on EF systems of regulatory control (e.g., Bierman, Nix, Greenberg, Blair, \& Domitrovich, 2008; Cicchetti, 2002). Note also that environmental influences often show substantial interactions with genetic factors, such that genetic vulnerability is only expressed among individuals exposed to environmental stressors, such as harsh parenting or family chaos (Asbury, Dunn, Pike, \& Plomin, 2003; Asbury, Wachs, \& Plomin, 2005).

Findings from children with traumatic brain injury indicate that higher-order brain functions (such as EF) are particularly vulnerable while they are still emerging. In their recent review of the effects of early brain injury on EF, Anderson et al. (2010) examined findings from children with focal brain pathology evident on MRI scan and compared EF performance in late childhood or adolescence for children who sustained early brain injury at each of six developmental periods (Congenital / Peri-natal / Infancy / Preschool / Mid Childhood / Late Childhood), with these six groups being matched for gender, SES, lesion size, location or laterality. Their findings showed that children who experienced brain injury very early in life displayed markedly more severe deficits in EF (and IQ). In other words, while the development of EF can be disrupted, with either transient or more permanent consequences, once established, EF skills are relatively robust (Johnson, 2005; 
Thomas \& Johnson, 2008). Consistent with this view, while Hughes, Roman and Ensor (2011) have reported significant inverse relations between exposure to maternal depression and preschool EF, no such association has been found in studies of older children or adolescents with depressed mothers (Klimes-Dougan, Ronsaville, Wiggs, \& Martinez, 2006; Micco et al., 2009).

Training studies and interventions. Intervention studies can be considered in two sets, of which the first set involves direct training on task analogues. For example, Kloo and Perner (2003) gave typically developing preschoolers a simplified version of the Wisconsin Card Sort task and found positive effects at post-test for both card-sorting training and false-belief training (each delivered in two sessions on separate days). More recently, Rueda et al. (2005) gave groups of 4- and 6-year-olds 5 days of attention training, and reported that low performers at pre-test showed the greatest gains, equivalent to half the difference between older and younger participants (i.e., the extent of gain expected from one year's difference in age). Similarly, in a recent review, Klingberg (2010) reported that training leads to significant improvements in working memory across a wide variety of age groups. However, not all aspects of EF appear so malleable to training. For example, (Thorell, Lindqvist, Nutley, Bohlin, \& Klingberg, 2009) found that a 5-week preschool training programme produced significant improvements in working memory but not in inhibitory control, suggesting that distinct processes underpin different aspects of EF. Finally, Karbach and Kray (2009) showed that training on task-switching led to positive effects that transferred to other EF tasks and to tests of fluid intelligence, both among school-aged children (aged 8- to 10-years) and in two groups of adults (aged 18- to 26years and 62- to 76-years). Interestingly, varying the training tasks reduced the 
improvements in children but increased improvements in adults. Clearly then, intervention designs need to be developmentally sensitive.

The second set of intervention studies adopt a broader and more naturalistic approach and are thus perhaps of greater relevance for theories of how everyday social environments might impinge on children's EF development. Randomized control trials (RCTs) have been used to assess at least three such interventions. The first of these, Head Start REDI (REsearch based, Developmentally Informed) is integrated into the Head Start pre-kindergarten programme for disadvantaged children and involves brief lessons, "handson" extension activities, and specific teaching strategies to promote social-emotional, linguistic and literacy skills. Bierman, Nix, Greenberg, Blair and Domitrovich (2008) reported that the REDI intervention led to significant improvements in children's task orientation, coupled with marginally significant gains in set-shifting performance. Another well-recognized intervention is the Vygotskian 'Tools in the Mind' preschool curriculum (Bodrova \& Leong, 1996; Diamond, Barnett, Thomas, \& Munro, 2007), which includes a variety of specially designed activities (e.g., socio-dramatic play, shared reading) that enable children to progress from external- to shared- to self- regulation; teachers are also trained to foster early skills in literacy and mathematics by encouraging reflective thinking and metacognition. Interestingly, although language plays a pivotal role in Vygotskian accounts of cognitive development, the Tools curriculum did not have a significant impact on language development (Barnett et al., 2008) but did appear to improve children's EF skills (note however that EF was only indexed indirectly by low problem behavior scores). The third RCT focused on an 8-week school-based intervention for older children (7- to 9year-olds) that aimed to promote mindful awareness practices (MAPs) through twice- 
weekly half-hour sessions. Echoing earlier results from preschoolers (e.g., Rueda, Rothbart, McCandliss, Saccomanno, \& Posner, 2005), Flook, Smalley, Kitil, Galla, Kaiser-

Greenland, Locke, Ishijima and Kasari (2010) reported that treatment-related gains in teacher and parent ratings of EF skills (both at school and at home) were particularly clear for less well-regulated children.

\section{Conclusions}

This review of two decades of developmental research on EF has covered considerable ground, including: (i) findings from typical and atypical groups across a broad developmental span (from infancy to adolescence); (ii) advances in assessment tools (e.g., development of child-friendly tasks, construction of questionnaire measures) and in statistical analysis (e.g., modeling both the structure of EF and developmental trajectories for $\mathrm{EF}$ ); (iii) the interplay between $\mathrm{EF}$ and other cognitive systems (e.g., those involved in children's developing understanding of mind, and in their processing of reward signals); (iv) integration of cognitive and neuroscience perspectives on EF (resulting in new models of how EF interacts with other cognitive systems); and (v) environmental factors that have either a positive influence (e.g., training/intervention programmes; parental scaffolding) or a negative influence (e.g., maltreatment, neglect, traumatic brain injury) on EF development.

Given the breadth of this review, it is interesting that several overarching themes emerged across the different sections. These include both continuities and contrasts in the substrates and correlates of EF in children of different ages. For example, from infancy through to adolescence, poor EF appears to be associated with risk taking and sensation 
seeking; this association highlights a developmental continuity in the interplay between top-down systems of EF and bottom-up reward-oriented systems. Indeed, research on several atypical groups, including children with ADHD, CD or problems of substance abuse, also highlights this interplay between top-down and bottom-up processes. Although not yet evident in research on autism, it is worth noting that the amygdala, which is a key substrate involved in reward processing, is central to at least one prominent account of autism (Baron-Cohen et al., 2000). Thus extending this dual focus on EF and reward processing to children with autism would appear a fruitful direction for future research.

A second notable developmental continuity is that, across a wide age range, typically developing individuals with good EF are more likely than their peers to do well on tests of theory of mind and show positive self-concepts, and are less likely than their peers to display antisocial behaviors. Perhaps related to these stable correlates of EF, longitudinal studies support EF as a predictor of later academic achievement in both young children and adolescents. Finally, across a wide variety of ages, at least some aspects of EF (e.g., working memory) appear malleable to training effects.

Examples of age-related contrasts include differences in the nature of EF: improvements in some aspects of EF (such as inhibitory control) can be seen from a very early age, while other aspects (e.g., planning) do not show marked improvements until much later on in development. Another important contrast concerns the extent to which EF can be associated with a localized neural base: age-related improvements in EF appear hand in hand with increased fronto-striatal activation, such that development is characterized by a progression from diffuse to specific neural substrate. Several age-related functional changes in children's performance on EF tasks suggest that this progressive 
localization of neural substrate may reflect increases in how strategic children and adolescents are when completing EF tasks. For example, adults and children differ markedly in how they respond to more challenging situations; while adults can reduce their speed of response to remain accurate, young children typically show a drop in accuracy. Similarly, young children are particularly likely to show an 'all or none' effect, in that they can inhibit a response if this is consistently required of them, but find it much harder to cope with situations that place varying demands on this system of inhibitory control. Finally, related to these contrasts in strategy use, training studies indicate an age-related contrast in the optimal format of the training tasks, with task variability increasing training benefits in adults, but reducing training benefits in children.

Together, the above age-related contrasts lead to a third key conclusion; namely the need to take developmental issues seriously when examining a construct such as EF that shows such a protracted developmental course. For example, if the differences noted above do indeed reflect an age-related contrast in strategy use on EF tasks, then the validity of across-age comparisons is in question, as different sets of skills may well underpin performance on the same task for children of different ages. An important first step in addressing this issue is to establish measurement invariance before comparing EF skills across different age groups (c.f. Hughes et al., 2010). Developmental issues are also raised by findings from studies of atypical groups. Thus, studies comparing different clinical groups (e.g., children with autism and children with ADHD) should be designed so that contrasts in developmental trajectories can be elucidated. The few existing studies that adopt a developmental perspective indicate that children with autism may show greater progress than children with ADHD, but the reasons for this are not yet known. 
The final conclusions to emerge from this review concern the interplay between EF and children's environments. First, although individual differences in EF have been viewed as almost entirely genetic in origin (e.g., Friedman et al., 2008), there is growing evidence that, for young children at least, environmental influences can be substantial. Thus, detailed longitudinal studies highlight the importance of family factors (e.g., maternal wellbeing, sensitivity and consistency of parenting). In addition, at least three randomized control trials show that early educational interventions have positive effects on EF, which may be: (i) strongest for children with low levels of EF (i.e., EF moderates the impact of interventions); (ii) pivotal to explaining the substantial improvement in children's behavior as a result of such interventions (i.e., EF is a mediator of intervention effects); and (iii) achieved indirectly, via improvements in children's theory-of-mind skills. Clearly then, tracing the mechanisms that underpin associations between family environments and children's growing EF skills, and between interventions and children's social and cognitive achievements are important challenges for future research. The stage is set for another very productive 20 years of research into children's developing EF skills! 


\section{References}

Aksan, N., \& Kochanska, G. (2004). Links between systems of inhibition from infancy to preschool years. Child Development, 75, 1477-1490.

Anderson, P. (2002). Assessment and development of executive function (EF) during childhood. Child Neuropsychology, 8, 71-82.

Anderson, P., Anderson, V., \& Garth, J. (2001). Assessment and development of organisational ability: The Rey Complex Figure organisational strategy score (RCFOSS). The Clinical Neuropsychologist, 15, 81-94.

Anderson, P., Anderson, V., \& Lajoie, G. (1996). The Tower of London Test: Validation and standardization for pediatric populations. The Clinical Neuropsychologist, 10, $54-65$.

Anderson, V., Anderson, P., Northam, E., Jacobs, R., \& Catroppa, C. (2001). Development of executive functions through late childhood and adolescence in an Australian sample. Developmental Neuropsychology, 20, 385-406.

Anderson, V., Spencer-Smith, M., Coleman, L., Anderson, P., Williams, J., Greenham, M., et al. (2010). Children's executive functions: Are they poorer after very early brain insult. Neuropsychologia, 48, 2041-2050.

Anderson, W. W., Damasio, H., Tranel, D., \& Damasio, A. R. (2001). Long-term sequelae of prefrontal cortex damage acquired in early childhood. Developmental Neuropsychology, 18, 281-296.

Apperly, I., Samson, D., \& Humphreys, G. (2009). Studies of Adults Can Inform Accounts of Theory of Mind Development. Developmental Psychology, 45, 190-201. 
Asbury, K., Dunn, J., Pike, A., \& Plomin, R. (2003). Nonshared environmental influences on individual differences in early behavioral development: A monozygotic twin differences study. Child Development, 74, 933-943.

Asbury, K., Wachs, T., \& Plomin, R. (2005). Environmental moderators of genetic influence on verbal and nonverbal abilities in early childhood. Intelligence, 33, 643661.

Aytaclar, S., Tarter, R., Kirisci, L., \& Sandy, L. (1999). Association between hyperactivity and executive cognitive functioning in childhood and substance use in early adolescence. Journal of the American Academy of Child and Adolescent Psychiatry, $38,172-178$.

Baillargeon, R., Spelke, E., \& Wasserman, S. (1985). Object permanence in five-month-old infants. Cognition, 20, 191-208.

Barnett, W., Jung, K., Yarosz, D., Thomas, J., Hornbeck, A., Stechuk, R., et al. (2008). Educational effects of the Tools of the Mind curriculum: A randomized trial. Early Childhood Research Quarterly, 23, 299-313.

Baron-Cohen, S., Ring, H., Bullmore, E., Wheelwright, S., Ashwin, C., \& Williams, S. (2000). The amygdala theory of autism. Neuroscience and Biobehavioral Reviews, $24,355-364$.

Bernier, A., Carlson, S., \& Whipple, N. (2010). From external regulation to self-regulation: Early parenting precursors of young children's executive functioning. Child Development, 81, 326-339.

Best, J., Miller, P., \& Jones, L. (2009). Executive functions after age 5: Changes and correlates. Developmental Review, 29 180-200. 
Bibok, M., Carpendale, J., \& Muller, U. (2009). Parental scaffolding and the development of executive function. New Directions in Child and Adolescent Psychiatry: Special Issue on social interaction and the development of executive function, 123, 17-34.

Bierman, K., Nix, R., Greenberg, M., Blair, C., \& Domitrovich, C. (2008). Executive functions and school readiness intervention: Impact, moderation, and mediation in the Head Start REDI program. . Development and Psychopathology, 20, 821-843.

Bishop, D., Aamodt-Leeper, G., Creswell, C., McGurk, R., \& Skuse, D. (2001). Individual differences in cognitive planning on the Tower of Hanoi task: Neuropsychological maturity or measurement error? Journal of Child Psychology and Psychiatry, 42, $551-556$.

Blair, C., Zelazo, P., \& Greenberg, M. (2005). The measurement of executive function in early childhood. Developmental Neuropsychology, 28 561-571.

Blakemore, S.-J., \& Choudhury, S. (2006). Development of the adolescent brain: Implications for executive function and social cognition. Journal of Child Psychology and Psychiatry and Allied Disciplines, 47, 296-312.

Bodrova, E., \& Leong, D. (1996). Tools of the Mind: The Vygotskian Approach to Early Childhood Education. Englewood Cliffs, New Jersey: Merrill/Prentice Hall.

Brocki, K., Clerkin, S., Guise, K., Fan, J., \& Fossella, J. (2009). Assessing the molecular genetics of the development of executive attention in children: focus on genetic pathways related to the anterior cingulate cortex and dopamine. Neuroscience, 164 , 241-246. 
Carlson, S. (2003). Executive function in context: Development, measurement, theory, and experience. Monographs of the Society for Research in Child Development, 68 138151.

Carlson, S., Mandell, D., \& Williams, L. (2004). Executive Function and Theory of Mind: Stability and Prediction From Ages 2 to 3. Developmental Psychology, 40, 11051122.

Carlson, S., \& Wang, T. (2007). Inhibitory control and emotion regulation in preschool children. Cognitive Development, 22, 489-510.

Chevignard, M., Catroppa, C., Galvin, J., \& Anderson, V. (2010). Development and evaluation of an ecological task to assess executive functioning post childhood TBI: The children's cooking task. Brain Impairment 11, 125-143.

Cicchetti, D. (2002). The impact of social experience on neurobiological systems: Illustration from a constructivist view of child maltreatment. Cognitive Development, , 17, 1407-1428.

Connor, P., Sampson, P., Bookstein, F., Barr, H., \& Streissguth, A. (2000). Direct and indirect effects of prenatal alcohol damage on executive function. Developmental Neuropsychology, 18 331-354.

Cuevas, K., \& Bell, M.A. (2010). Developmental progression of looking and reaching performance on the a-not-b task. Developmental Psychology, 46, 1363-1371

Davidson, M., Amso, D., Anderson, L., \& Diamond, A. (2006). Development of cognitive control and executive functions from 4 to 13 years: Evidence from manipulations of memory, inhibition, and task switching. Neuropsychologia, 44, 2037-2078.

De Bellis, M. (2005). The psychobiology of neglect. Child Maltreatment, 10, 150-172. 
De Luca, C., Wood, S., Anderson, V., Buchanan, J., Profitt, T., Mahoney, K., et al. (2003). Normative data from the CANTAB: Development of executive function over the lifespan. Journal of Clinical and Experimental Neuropsychology, 25, 242-254.

de Vignemont, F. (2009). Drawing the boundary between low-level and high-level mindreading. Philosophical Studies, 144, 457-466.

Dennis, M., Agostino, A., Roncadin, C., \& Levin, H. (2009). Theory of mind depends on domain-general executive functions of working memory and cognitive inhibition in children with traumatic brain injury. Journal of Clinical and Experimental Neuropsychology, 31, 835-847.

Diamond, A. (1988). Abilities and neural mechanisms underlying A not B performance. Child Development, 59, 523-527.

Diamond, A. (2002). Normal development of prefrontal cortex from birth to young adulthood: Cognitive functions, anatomy, and biochemistry. In D. Stuss \& R. Knight (Eds.), Principles of frontal lobe function (pp. 466-503). London, UK: Oxford University Press.

Diamond, A. (2009). All or None Hypothesis: A Global-Default Mode That Characterizes the Brain and Mind. Developmental Psychology, 45, 130-138.

Diamond, A., Barnett, W., Thomas, J., \& Munro, S. (2007). Preschool program improves cognitive control. Science, 318, 1387-1388.

Diamond, A., \& Goldman-Rakic, P. (1989). Comparison of human infants and rhesus monkeys on Piaget's A-not-B task: Evidence for dependence on dorsolateral prefrontal cortex. Experimental Brain Research, 74, 24-40. 
Diamond, A., Prevor, M., Callender, G., \& Druin, D. (1997). Prefrontal cortex cognitive deficits in children treated early and continuously for PKU. Monographs of the Society for Research in Child Development, 62.

Diamond, A., Zola-Morgan, S., \& Squire, L. (1989). Successful Performance by Monkeys With Lesions of the Hippocampal Formation on $\mathrm{AB}^{-}$and Object Retrieval, Two Tasks That Mark Developmental Changes in Human Infants. Behavioral Neuroscience, 103, 526-537.

Dumontheil, I., Apperly, I., \& Blakemore, S.-J. (2010). Online usage of theory of mind continues to develop in late adolescence. Developmental Science, 13, 331-338.

Emslie, H., Wilson, C., Burden, V., Nimmo-Smith I. \& Wilson B.A. (2003) Behavioural Assessment for Dysexecutive Syndrome: Children's version. Thames Valley Test Company, UK

Ensor, R., Roman, G., \& Hughes, C. (in preparation). Links between Maternal Depression and Parental Self-Efficacy and Satisfaction and Preschool Executive Function

Fairchild, G., van Goozen, S., Stollery, S., Aitken, M., Savage, J., Moore, S., et al. (2009). Decision Making and Executive Function in Male Adolescents with Early-Onset or Adolescence-Onset Conduct Disorder and Control Subjects. Biological Psychiatry, 66 162-168.

Flook, L., Smalley, S., Kitil, M., Galla, B., Kaiser-Greenland, S., Locke, J., et al. (2010). Effects of mindful awareness practices on executive functions in elementary school children. Journal of Applied School Psychology, 26, 70-95.

Flynn, E. (2006). A microgenetic investigation of stability and continuity in theory of mind development. British Journal of Developmental Psychology, 24, 631-654. 
Friedman, N., Miyake, A., Young, S., DeFries, J., Corley, R., \& Hewitt, J. (2008). Individual Differences in Executive Functions Are Almost Entirely Genetic in Origin. Journal of Experimental Psychology: General, 137, 201-225.

Garon, N., Bryson, S., \& Smith, I. (2008). Executive function in preschoolers: A review using an integrative framework. Psychological Bulletin, 134, 31-60.

Geurts, H., Verté, S., Oosterlaan, J., Roeyers, H., \& Sergeant, J. (2004). How specific are executive functioning deficits in attention deficit hyperactivity disorders and autism? Journal of Child Psychology and Psychiatry and Allied Disciplines, 45, 836-854.

Giedd, J., Blumenthal, Jeffries, N., Castellanos, F., Liu, H., Zijdenbos, A., et al. (1999). Brain development during childhood and adolescence: A longitudinal MRI study. Nature Neuroscience., 2, 861-863.

Gioia, G., Isquith, P., Retzlaff, P., \& Espy, K. (2002). Confirmatory factor analysis of the Behavior Rating Inventory of Executive Function (BRIEF) in a clinical sample. Child Neuropsychology, 8, 249-257.

Goldberg, M., Mostofsky, S., Cutting, L., Mahone, E., Astor, B., Denckla, M., et al. (2005). Subtle executive impairment in children with autism and children with ADHD. Journal of Autism and Developmental Disorders, 35, 279-293.

Golden, C. J. (1981). The Luria-Nebraska Children's Battery: Theory and formulation. In G. W. Hynd \& G. E. Obrzut (Eds.), Neuropsychological assessment and the schoolaged child (pp. 277-302). New York: Grune \& Stratton.

Green, C., Mihic, A., Nikkel, S., Stade, B., Rasmussen, C., Munoz, D., et al. (2009). Executive function deficits in children with fetal alcohol spectrum disorders 
(FASD) measured using the Cambridge Neuropsychological Tests Automated Battery (CANTAB). Journal of Child Psychology and Psychiatry and Allied Disciplines, 50, 688-697.

Happé, F., Hughes, C., Booth, R., \& Charlton, R. (2006). Executive dysfunction in Autism Spectrum Disorders and Attention Deficit/Hyperactivity Disorder: Developmental profiles. Brain and Cognition (special issue on Asperger's syndrome), 61, 25-39.

Harris, P. (1975). Development of search and object permanence during infancy. Psychological Bulletin, 82, 332-344.

Hill, E. (2004). Executive function in autism. Trends in Cognitive Sciences, 8, 26-32.

Hooper, C., Luciana, M., Conklin, H., \& Yarger, R. (2004). Adolescents’ performance on the development of decision making and ventromedial prefrontal cortex. Developmental Psychology, 40, 1148-1158.

Hughes, C., (2002). Executive Functions and Development: Emerging Themes. Infant and Child Development, Special Issue on Executive Functions and Development, 11, 201-210

Hughes, C., Dunn, J., \& White, A. (1998). Trick or treat?: Uneven understanding of mind and emotion and executive function among "hard to manage" preschoolers. Journal of Child Psychology and Psychiatry \& Allied Disciplines, 39, 981-994.

Hughes, C., \& Ensor, R. (2005). Theory of Mind and Executive Function in 2-year-olds: A family affair? Developmental Neuropsychology, 28, 645-668.

Hughes, C., \& Ensor, R. (2007). Executive Function and Theory of Mind: Predictive relations from ages 2- to 4-years. Developmental Psychology, 43, 1447-1459. 
Hughes, C., \& Ensor, R. (2009). How do families help or hinder the development of executive function? New Directions in Child and Adolescent Psychiatry: Special Issue on social interaction and the development of executive function, 123, 35-50.

Hughes, C., Ensor, R., Wilson, A., \& Graham, A. (2010). Tracking Executive Function Across the Transition to School:A Latent Variable Approach. Developmental Neuropsychology, 35, 20-36.

Hughes, C., \& Graham, A. (2002). Measuring executive functions in childhood: Problems \& solutions? Child and Adolescent Mental Health, 7, 131-142.

Hughes, C., \& Russell, J. (1993). Autistic children's difficulty with mental disengagement from an object: Its implications for theories of autism. Developmental Psychology, $29,498-510$.

Hughes, C., Russell, J., \& Robbins, T. (1994). Evidence for central executive dysfunction in autism. Neuropsychologia, 32, 477-492.

Huizinga, M., Dolan, C., \& van der Molen, M. (2006). Age-related change in executive function: Developmental trends and a latent variable analysis. Neuropsychologia, 44, 2017-2036.

Jacobs, E., Miller, L., \& Tirella, L. (2010). Developmental and behavioral performance of internationally adopted preschoolers: A pilot study. Child Psychiatry and Human Development, 41, 15-29.

Jarrold, C., Mansergh, R., \& Whiting, C. (2010). The representational status of pretence: Evidence from typical development and autism. British Journal of Developmental Psychology, 28, 239-254. 
Johnson, M. (2005). Sensitive periods in functional brain development: Problems and prospects. Developmental Psychobiology, 46 287-292.

Karbach, J., \& Kray, J. (2009). How useful is executive control training? Age differences in near and far transfer of task-switching training. Developmental Science, 12, 978990.

Klimes-Dougan, B., Ronsaville, D., Wiggs, E., \& Martinez, P. (2006). Neuropsychological Functioning in Adolescent Children of Mothers with a History of Bipolar or Major Depressive Disorders. Biological Psychiatry, 60 957-965.

Klingberg, T. (2010). Training and plasticity of working memory. Trends in Cognitive Sciences, 14 317-324.

Klingberg, T., Olesen, P., Johnson, M., Gustafsson, P., Dahlström, K., Gillberg, C., et al. (2005). Computerized training of working memory in children with ADHD - A randomized, controlled trial. Journal of the American Academy of Child and Adolescent Psychiatry, 44, 177-186.

Kloo, D., \& Perner, J. (2003). Training transfer between card sorting and false belief understanding: Helping children apply conflicting descriptions. Child Development, 74, 1823-1839.

Kovas, Y., Haworth, C., Dale, P., \& Plomin, R. (2007). The Genetic and Environmental Origins of Learning Abilities and Disabilities in the Early School Years (Vol. 72). Boston: Blackwell.

Krikorian, R., Bartok, J., \& Gay, N. (1994). Tower of London procedure: A standard method and developmental data. Journal of Clinical and Experimental Neuropsychology, 16, 840-850. 
Lackner, C., Bowman, L., \& Sabbagh, M. (2010). Dopaminergic functioning and preschoolers' theory of mind. Neuropsychologia, 48, 1767-1774.

Lehto, J., Juujärvi, P., Kooistra, L., \& Pulkkinen, L. (2003). Dimensions of executive functioning: Evidence from children. British Journal of Developmental Psychology, $21,59-80$.

Lejeune, B., Beebe, D., Noll, J., Kenealy, L., Isquith, P., \& Gioia, G. (2010). Psychometric support for an abbreviated version of the behavior rating inventory of executive function (BRIEF) parent form. Child Neuropsychology, 16, 182-201.

Levine, B., Robertson, I.H., Clare, L., Carter, G., Hong, J., Wilson, B.A., Duncan, J., Stuss, D.T.(2000). Rehabilitation of executive functioning: An experimental-clinical validation of goal management training. Journal of the International Neuropsychological Society, 6, 299-312

Lewis, C., \& Carpendale, J. (2009). Introduction: Links between social interaction and executive function. New Directions in Child and Adolescent Psychiatry: Special Issue on social interaction and the development of executive function, 123, 1-16.

Luciana, M. (2003). Practitioner review: Computerized assessment of neuropsychological function in children: Clinical and research applications of the Cambridge Neuropsychological Testing Automated Battery (CANTAB) Journal of Child Psychology and Psychiatry 45, 649-663.

Luciana, M., Conklin, H., Cooper, C., \& Yarger, R. (2005). The development of nonverbal working memory and executive control processes in adolescents. Child Development, 76, 697-712. 
Luna, B., Garver, K., Urban, T., Lazar, N., \& Sweeney, J. (2004). Maturation of cognitive processes from late childhood to adulthood. Child Development 75, 1357-1372.

Luria, A. R. (1966). Higher cortical functions in man (1st ed.). New York, USA: Basic Books.

Mattson, S., Goodman, A., Caine, C., Delis, D., \& Riley, E. (1999). Executive functioning in children with heavy prenatal alcohol exposure. Alcoholism: Clinical and Experimental Research, 23, 1808-1815.

McAuley, T., Chen, S., Goos, L., Schachar, R., \& Crosbie, J. (2010). Is the behavior rating inventory of executive function more strongly associated with measures of impairment or executive function? Journal of the International Neuropsychological Society, 16, 495-505.

Micco, J., Henin, A., Biederman, J., Rosenbaum, J., Petty, C., Rindlaub, L., et al. (2009). Executive functioning in offspring at risk for depression and anxiety. Depression and Anxiety, 26, 780-790.

Miyake, A., Friedman, N., Emerson, M., Witzki, A., Howerter, A., \& Wager, T. (2000). The unity and diversity of executive functions and their contributions to complex "frontal lobe" tasks: A latent variable analysis. Cognitive Psychology, 41, 49-100.

Montague, P., Hyman, S., \& Cohen, J. (2004). Computational roles for dopamine in behavioural control. Nature, 431, 760-767.

Mosconi, M., Kay, M., D'Cruz, A.-M., Seidenfeld, A., Guter, S., Stanford, L., et al. (2009). Impaired inhibitory control is associated with higher-order repetitive behaviors in autism spectrum disorders. Psychological Medicine, 39, 1559-1566. 
Mulder, H., Pitchford, N., Hagger, M., \& Marlow, N. (2009). Development of executive function and attention in preterm children: A systematic review. Developmental Neuropsychology, 34, 393-421.

Munakata, Y. (2001). Graded representations in behavioral dissociations. Trends in Cognitive Sciences, 5 309-315.

Noble, K., Norman, M. F., \& Farah, M. (2005). Neurocognitive correlates of socioeconomic status in kindergarten children. Developmental Science, 8, 74-87.

O'Hearn, K., Asato, M., Ordaz, S., \& Luna, B. (2008). Neurodevelopment and executive function in autism. Development and Psychopathology, 20 1103-1132.

Ozonoff, S., (1995) Reliability and validity of the Wisconsin Card Sorting Test in studies of autism. Neuropsychology, 9, 491-500

Ozonoff, S., Cook, I., Coon, H., Dawson, G., Joseph, R., Klin, A., et al. (2004). Performance on Cambridge neuropsychological test automated battery subtests sensitive to frontal lobe function in people with autistic disorder: Evidence from the Collaborative Programs of Excellence in Autism network. . Journal of Autism and Developmental Disorders, 34, 139-150.

Ozonoff, S., Pennington, B. F., \& Rogers, S. J. (1991). Executive function deficits in high functioning autistic children: Relationship to theory of mind. Journal of Child Psychology and Psychiatry, 32, 1081-1105.

Paus, T. (2010). Growth of white matter in the adolescent brain: Myelin or axon? Brain and Cognition, 72, 26-35. 
Pellicano, E. (2007). Links between theory of mind and executive function in young children with autism: Clues to developmental primacy. Developmental Psychology, 43, 974-990.

Pellicano, E. (2010). Individual Differences in Executive Function and Central Coherence Predict Developmental Changes in Theory of Mind in Autism. Developmental Psychology, 46, 530-544.

Pennington, B., \& Ozonoff, S. (1996). Executive function and developmental psychopathology. Journal of Child Psychology and Psychiatry, 37, 51-87.

Perner, J., \& Aichhorn, M. (2008). Theory of mind, language and the temporoparietal junction mystery. Trends in Cognitive Sciences, , 12, 123-126. .

Perner, J., Aichhorn, M., Kronbichler, M., Staffen, W., \& Ladurner, G. (2006). Thinking of mental and other representations: the roles of left and right temporo-parietal junction. Social neuroscience 1 245-258.

Perner, J., Ruffman, T., \& Leekam, S. (1994). Theory of mind is contagious: You catch it from your sibs. Child Development, 65, 1228-1238.

Rasmussen, C., Wyper, K., \& Talwar, V. (2009). The relation between theory of mind and executive functions in children with fetal alcohol spectrum disorders. The Canadian journal of clinical pharmacology, 16, 370-380.

Romer, D., Betancourt, L., Giannetta, J., Brodsky, N., Farah, M., \& Hurt, H. (2009). Executive cognitive functions and impulsivity as correlates of risk taking and problem behavior in preadolescents. . Neuropsychologia, 47, 2916-2926.

Rothbart, M., Derryberry, D., \& Hershey, K. (2000). Stability of temperament in childhood: Laboratory infant assessment to parent report at seven years. In V. 
Molfese \& D. Molfese (Eds.), Temperament and personality development across the life span (pp. 85).

Rothbart, M., Ellis, L., Rueda, M., \& Posner, M. (2003). Developing mechanisms of temperamental effortful control Journal of Personality, 71, 1113-1144.

Rueda, M., Rothbart, M., McCandliss, B., Saccomanno, L., \& Posner, M. (2005). Training, maturation, and genetic influences on the development of executive attention. Proceedings of the National Academy of Sciences of the United States of America, 102 14931-14936.

Rutter, M., \& O'Connor, T. (2004). Are There Biological Programming Effects for Psychological Development? Findings from a Study of Romanian Adoptees. Developmental Psychology, 40, 81-94.

Sabbagh, M., Bowman, L., Evraire, L., \& Ito, J. (2009). Neurodevelopmental correlates of theory of mind in preschool children. Child Development, 80, 1147-1162.

Schonfeld, A., Mattson, S., Lang, A., Delis, D., \& Riley, E. (2001). Verbal and nonverbal fluency in children with heavy prenatal alcohol exposure. Journal of Studies on Alcohol, 62, 239-246.

Sheese, B., Rothbart, M., Posner, M., White, L., \& Fraundorf, S. (2008). Executive attention and self-regulation in infancy. Infant Behavior and Development, 31, 501510.

Solomon, M., Ozonoff, S., Ursu, S., Ravizza, S., Cummings, N., Ly, S., et al. (2009). The neural substrates of cognitive control deficits in autism spectrum disorders Neuropsychologia, 47, 2515-2526. 
Sonuga-Barke, E. (2005). Causal models of attention-deficit/hyperactivity disorder: From common simple deficits to multiple developmental pathways. Biological Psychiatry, 57, 1231-1238.

Tager-Flusberg, H. (2001). A re-examination of the Theory of Mind hypothesis of autism. In J. Burack, T. Charman, N. Yirmiya \& P. Zelazo (Eds.), The development of autism: Perspectives from theory and research (pp. 173-194). Mahwah, NJ: Lawrence Erlbaum Associates.

Tau, G., \& Peterson, B. (2010). Normal development of brain circuits. Neuropsychopharmacology, 35, 147-168.

Thomas, M., \& Johnson, M. (2008). New advances in understanding sensitive periods in brain development. Current Directions in Psychological Science, 17, 1-5.

Thorell, L., Lindqvist, S., Nutley, S., Bohlin, G., \& Klingberg, T. (2009). Training and transfer effects of executive functions in preschool children. Developmental Science, 12, 106-113.

Vaurio, L., Riley, E., \& Mattson, S. (2008). Differences in executive functioning in children with heavy prenatal alcohol exposure or attention-deficit/hyperactivity disorder. Journal of the International Neuropsychological Society, 14 119-129.

Vygotsky, L. (1978). Mind in society: The development of higher psychological processes. Cambridge MA: Harvard University Press.

Welsh, M. C., Pennington, B. F., \& Groisser, D. B. (1991). A normative-developmental study of executive function: A window on prefrontal function in children. Developmental Neuropsychology, 7, 131-149. 
White, S., Burgess, P., \& Hill, E. (2009). Impairments on "open-ended" executive function tests in Autism. Autism Research, 2, 138-147.

Wiebe, S., Espy, K., \& Charak, D. (2008). Using confirmatory factor analysis to understand executive control in preschool children: I. Latent structure. Developmental Psychology, 44, 575-587.

Wiebe, S., Sheffield, T., Nelson, J., Clark, C., Chevalier, N., \& Espy, K. (2010). The structure of executive function in 3-year-olds. Journal of Experimental Child Psychology, doi:10.1016/j.jecp2010.1008.1008.

Wiers, R., Bartholow, B., van den Wildenberg, E., Thush, C., Engels, R., Sher, K., et al. (2007). Automatic and controlled processes and the development of addictive behaviors in adolescents: A review and a model. Pharmacology Biochemistry and Behavior, 86 263-283.

Willoughby, M., Wirth, R., \& Blair, C. (2010). Contributions of modern measurement theory to measuring executive function in early childhood: An empirical demonstration. Journal of Experimental Child Psychology, doi:10.1016/j.jecp.2010.1004.1007.

Zelazo, P., Muller, U., Frye, D., \& Marcovitch, S. (2003). The development of executive function: Cognitive complexity and control--revised. Monographs of the Society for Research in Child Development, 68, 93-119. 